\title{
Histone acetylation and deacetylation: importance in inflammatory lung diseases
}

\author{
P.J. Barnes, I.M. Adcock and K. Ito
}

ABSTRACT: Inflammatory lung diseases are characterised by increased expression of multiple inflammatory genes that are regulated by proinflammatory transcription factors, such as nuclear factor-кB. Gene expression is regulated by acetylation of core histones through the action of coactivators, such as CREB-binding protein, with intrinsic histone acetyltransferase (HAT) activity.

Conversely, gene repression is mediated via histone deacetylases (HDACs) and other corepressors. In asthma, there is an increase in HAT activity and some reduction in HDAC activity, which is restored by corticosteroid therapy. Corticosteroids switch off inflammatory genes in asthma through the inhibition of HAT activity and by the recruitment of HDAC2 to the activated inflammatory gene complex. In chronic obstructive pulmonary disease, there is a reduction in HDAC2 activity and expression, which may account for the amplified inflammation and resistance to the actions of corticosteroids. The reduction in HDAC2 may be secondary to oxidative and nitrative stress as a result of cigarette smoking and severe inflammation, and may also occur in severe asthma, smoking asthmatic patients and cystic fibrosis.

Similar mechanisms may also account for the steroid resistance seen with latent adenovirus infections. The reduction in histone deacetylase activity can be restored by theophylline, which may be able to reverse steroid resistance in chronic obstructive pulmonary disease and other inflammatory diseases.

KEYWORDS: Chromatin, histone acetylation, histone acetyltransferase, histone deacetylate, transcription factor

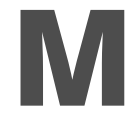
any of the commonest lung diseases, including asthma, chronic obstructive pulmonary disease (COPD), cystic fibrosis, interstitial lung disease and acute respiratory distress syndrome, involve inflammation, with the coordinate expression of multiple inflammatory genes in the lungs. These inflammatory genes code for the expression of cytokines, chemokines, enzymes that synthesise inflammatory mediators, inflammatory mediator receptors and adhesion molecules, resulting in a coordinated influx and activation of inflammatory cells. Many of these inflammatory genes are regulated by proinflammatory transcription factors, including nuclear factor (NF)- $\kappa \mathrm{B}$ and activator protein (AP)-1. These transcription factors orchestrate, amplify and perpetuate the inflammatory response and form the molecular basis of chronic inflammation [1-3]. Recently, much more has been learned about the molecular mechanisms that switch on inflammatory genes and, even more importantly, the mechanisms for switching off these genes that can be exploited in therapy. Modification of core histones, around which DNA is wound within the chromosomes, plays a critical role in regulating the expression of all genes, and in determining which genes are activated and which genes are repressed. Histone acetylation is a major modification that affects gene transcription and is controlled by histone acetyltransferases (HATs). In contrast, histone deacetylases (HDACs), which remove the acetyl groups from hyperacetylated histones, counteract the effects of HATs and return histone to its basal state, with the concomitant suppression of gene transcription. This review focuses on the critical role of histone acetylation in the regulation of inflammatory genes. Understanding the role of histone acetylation is now providing important insights into the mechanism of action of corticosteroids in treating inflammatory diseases, such as asthma, and the mechanisms of resistance to

\section{AFFILIATIONS}

National Heart and Lung Institute, Imperial College, London, UK.

\section{CORRESPONDENCE}

P.J. Barnes

National Heart and Lung Institute Imperial College School of Medicine Dovehouse St London SW3 6LY UK

Fax: 442073515675

E-mail: p.j.barnes@imperial.ac.uk

Received:

October 132004

Accepted after revision:

November 302004 
steroids in COPD and other severe inflammatory lung diseases. These new concepts are now also pointing the way towards the development of novel therapeutic approaches.

\section{HISTONES AND CHROMATIN REMODELLING}

Since the 1960s, it has been recognised that acetylation of histones and remodelling of the tightly packed chromatin structure is associated with gene induction [4]. However, only in the last 8 yrs have the molecular mechanisms whereby inflammatory genes are switched on by transcription factors and histone acetylation become much better understood. Alteration of the structure of chromatin is critical to the regulation of gene expression. Chromatin is made up of nucleosomes, which are particles consisting of DNA associated with an octomer of two molecules each of the core histone proteins (H2A, H2B, H4 and H4), around which 146 base pairs of DNA are wound (fig. 1). In the resting cell, DNA is wound tightly around these basic core histones, excluding the binding of the enzyme RNA polymerase II, which activates the formation of messenger RNA. This conformation of the chromatin structure is described as closed, and is associated with the suppression of gene expression. Gene transcription only occurs when the chromatin structure is opened up, with unwinding of DNA so that RNA polymerase II and basal transcription complexes can now bind to the naked DNA to initiate transcription. When proinflammatory transcription factors, such as NF- $\mathrm{B}$, are activated, they bind to specific recognition sequences in DNA and subsequently interact with large coactivator molecules, such as CREB-binding protein (CBP), p300 and p300/CBP-associated factor (PCAF; fig. 2). These coactivator molecules act as the molecular switches that control gene transcription and all have intrinsic HAT activity $[5,6]$. Each core histone has a long terminal, which is rich in lysine residues that may be acetylated, thus changing the electrical charge of the core histone. This results in acetylation of core histones, thereby reducing their charge, which allows the chromatin structure to transform from the resting closed conformation to an activated open form [6]. Thus, this allows

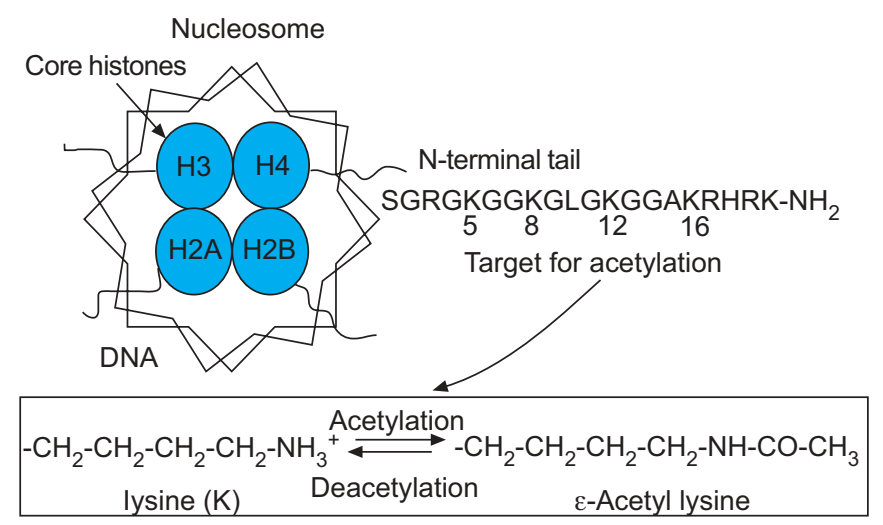

FIGURE 1. The structure of chromatin. DNA is wound around nucleosomes, which are composed of eight histone molecules with two copies of histones H2A, $\mathrm{H} 2 \mathrm{~B}, \mathrm{H} 3$ and $\mathrm{H} 4$. Each histone molecule has a long tail rich in lysine residues $(\mathrm{K})$, which are the sites of enzymatic modification, such as acetylation, thus changing the charge of the molecule and leading to DNA unwinding.

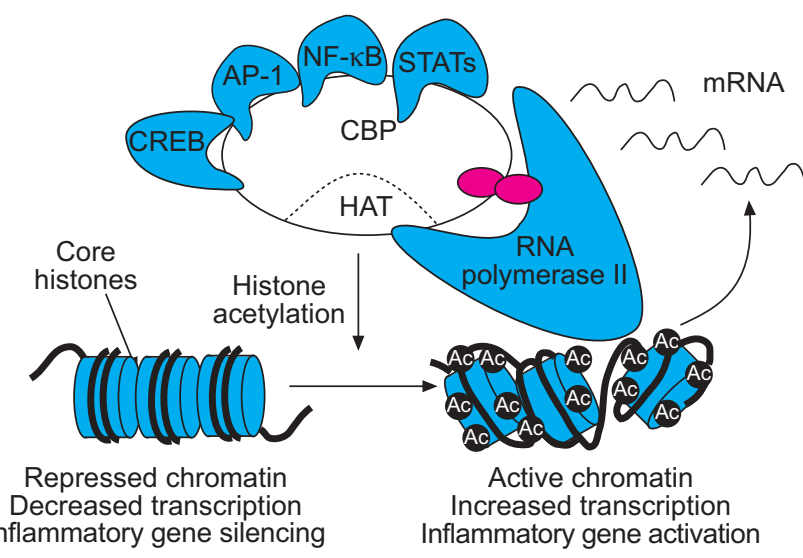

FIGURE 2. Coactivators, such as CREB-binding protein (CBP), have intrinsic histone acetyltransferase (HAT) activity, resulting in opening up to the chromatin structure, which allows binding of RNA polymerase II and initiation of gene transcription. Several transcription factors interact with CBP, including cyclic AMP response element binding protein (CREB), nuclear factor (NF)- $\mathrm{KB}$, activator protein (AP)-1 and signal transduction activated transcription factors (STATs).

binding of TATA box-binding protein (TBP), TBP-associated factors and, finally, RNA polymerase II, which initiates gene transcription (fig. 3). This molecular mechanism is probably common to all genes, including those involved in differentiation, proliferation and activation of cells. Just as acetylation of histones is associated with gene induction, the removal of acetyl groups by HDACs is associated with repacking of chromatin and a lack of gene expression or gene silencing (fig. 3) [7].

Recently, these fundamental mechanisms have been applied in understanding the regulation of inflammatory genes that become activated in airway diseases. In a human epithelial cell line, activation of NF- $\kappa \mathrm{B}$ (induced by exposing the cell to inflammatory signals, such as interleukin (IL)-1 $\beta$, tumour

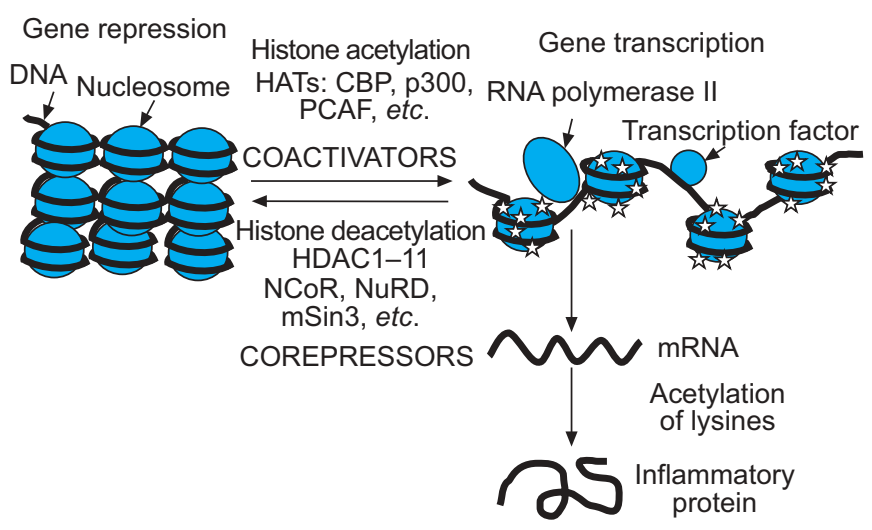

FIGURE 3. Gene activation and repression are regulated by acetylation of core histones. Histone acetylation is mediated by coactivators that have intrinsic histone acetyltransferase (HAT) activity, opening up the chromatin structure to allow binding of RNA polymerase II and transcription factors that were unable to bind DNA in the closed chromatin configuration. This is reversed by corepressors, which include histone deacetylases (HDACs) and other associated corepressors that reverse this acetylation, thereby causing gene silencing. CBP: CREB-binding protein; PCAF: p300/CBP-associated factor; NCoR: nuclear receptor corepressor. 
necrosis factor (TNF)- $\alpha$ or endotoxin) results in acetylation of specific lysine residues on histone $\mathrm{H} 4$ (histone $\mathrm{H} 3$ does not appear to be so markedly or rapidly acetylated by inflammatory signals), and this is correlated with an increased expression of inflammatory genes, such as granulocytemacrophage colony-stimulating factor (GM-CSF) [8]. There is a specific pattern of acetylation of histone $\mathrm{H} 4$ with preferential acetylation of lysines 8 and 12, and relative sparing of the other two potential targets for acetylation of lysine residues on the N-terminal tail (lysine 5 and lysine 16) [8].

\section{HISTONE DEACETYLASES}

HDACs play a critical role in the suppression of gene expression by reversing the hyperacetylation of core histones. Eleven HDACs that deacetylate histones are now recognised in mammalian cells $[9,10]$ and are classified into two major classes. Class I includes HDAC1, 2, 3, 8 and 11, which bear significant homology to the yeast protein RPD3 and are mainly localised to the nucleus. Class II includes HDAC4, 5, 6, 7, 9 and 10 , which are homologous to yeast HAD-1-like enzymes and shuttle between nucleus and cytoplasm. Class I HDACs are widely expressed and are found in most cell types, whereas class II HDACs appear to have a more restricted distribution and may be involved in cellular differentiation. Some HDACs also deacetylate nonhistone proteins such as $\alpha$-tubulin, p53, p65 and MyoD. There is evidence that these different HDACs target different patterns of acetylation and regulate different genes [11]. The different HDACs are also likely to be regulated differently. HDACs interact with corepressor molecules, such as nuclear receptor corepressor, ligand-dependent corepressor, NuRD and mSin3, all of which aid HDACs in gene repression and may provide specificity by selecting which genes are switched off by HDAC $[12,13]$.

Trichostatin A (TSA) is a nonselective inhibitor of HDACs [14] and, in alveolar macrophages and airway epithelial cell lines, it leads to increased expression of inflammatory genes, such as GM-CSF and IL-8, after activation with inflammatory stimuli $[8,15,16]$. This suggests that HDACs normally act to repress the expression of inflammatory genes.

As well as histones, other transcription factors, such as GATA3 and the p65 component of NF- $\kappa \mathrm{B}$, are targets for acetylation and deacetylation, which thereby modulate their transcriptional activity. Thus, HDACs are also associated with inactive p65 and play a role in the regulation of NF- $\mathrm{BB}-$ mediated gene transcription without altering DNA binding [17-19]. CBP acetylates specific lysine residues on p65, increasing its binding to DNA and causing transcriptional activation. HDACs reverse this process; HDAC1 and HDAC2 are able to deacetylate acetylated NF- $\mathrm{\kappa B}$ and promote its association with the inhibitor IкB- $\alpha$ within the nucleus, in order to promote export into the cytoplasm and, thus, terminate the activity of $\mathrm{NF}-\kappa \mathrm{B}$ [18]. Inhibition of these HDACs by TSA results in increased activation of NF- $\kappa B$ and increased expression of inflammatory genes, such as IL-8. Furthermore, changes in the phosphorylation status can switch p65 from interacting with a corepressor (HDAC) to a coactivator CBP (HAT) [19].

A third class of deacetylases are the atypical nicotinamide adenosine dinucleotide-dependent sirtuins. These proteins deacetylate nonhistone proteins and are thought to play a role in programmed cell death in mononuclear cells $[20,21]$. For example SIRT1, the mammalian equivalent of the yeast silencing information regulator 2 , can deacetylate p53, thereby inactivating p53-mediated transcription and apoptosis, regulate Bax-induced apoptosis by deacetylating Ku70 and prevent Forkhead-mediated cell death [22]. Recently, SIRT1 has also been reported to deacetylate p65 and control apoptosis in a lung cancer cell line [22].

\section{HISTONE DEACETYLASES IN AIRWAY DISEASES \\ Asthma}

In bronchial biopsies from patients with asthma, there is a marked increase in HAT and a small reduction in HDAC activity compared with normal airways, thus favouring increased inflammatory gene expression [23]. Similar changes are found in alveolar macrophages obtained by bronchoalveolar lavage from patients with asthma [24]. There is a small reduction in the expression of HDAC1, but expression of HDAC2 and HDAC3 is normal in these cells. Peripheral blood mononuclear cells (lymphocytes and monocytes) appear to have normal HAT and HDAC activity, indicating that these changes occur locally in the airways of asthmatic patients. Interestingly, in patients with asthma who smoke, there is a significantly greater reduction of HDAC activity in bronchial biopsies than in nonsmoking asthmatic patients [25], and this may account for why these smoking asthmatics have more severe asthma and resistance to steroids [26].

\section{Chronic obstructive pulmonary disease}

In COPD, there is a marked reduction in HDAC activity in the lung parenchyma, and this decrease is correlated with disease severity [27]. The reduction in HDACs in the peripheral lung is selective with a marked reduction in HDAC2, with lesser reduction in HDAC5 and HDAC8 expression, but normal expression of the other HDACs. Furthermore, HDAC5 expression is predominantly cytoplasmic, rather than nuclear, in patients with COPD. In patients with very severe disease (Global Initiative for Chronic Obstructive Lung Disease (GOLD) stage 4 ), there is a $>95 \%$ reduction in the expression of HDAC2. The reduction in HDAC activity is related to the intensity of inflammation, as measured by expression of IL-8 and the number of inflammatory cells in small airways [28]. Reduced HDAC activity is also related to resistance to the anti-inflammatory effects of corticosteroids, a characteristic feature of COPD. HAT activity is increased and HDAC2 activity is reduced in lungs of rats exposed to cigarette smoke, which show increased NF- $\kappa$ B activation and expression of inflammatory genes [29]. By contrast, HAT activity is not increased in COPD patients as it is in asthma, indicating that increased gene transcription in inflammatory diseases may be due to increased HAT, decreased HDAC or a combination of both. Alveolar macrophages from normal smokers also show a reduction in HDAC activity and expression of HDAC2, and this is correlated with an increase in release of TNF- $\alpha$ and IL- 8 in response to an inflammatory stimulus [30]. There is a further reduction in HDAC activity and expression of HDAC2 in alveolar macrophages from COPD patients. 


\section{MECHANISMS OF HISTONE DEACETYLASE IMPAIRMENT}

\section{Oxidative and nitrative stress}

Oxidative stress acetylates histone $\mathrm{H} 4$ in epithelial cell lines, such as A549 and BEAS-B, resulting in an increased release of inflammatory proteins, such as IL-8 $[16,31]$. This involves the activation of the transcription factor NF- $\kappa \mathrm{B}$, which has long been known to be activated by oxidative stress. Oxidative stress also increases the association between the p65 component of NF- $\kappa$ B and CBP [32]. The increase in HAT activity may be due to a decrease in HDAC activity, and oxidative stress (hydrogen peroxide) markedly reduces HDAC activity and HDAC2 expression in epithelial cell lines in vitro [33]. Hydrogen peroxide and cigarette smoke condensate induce acetylation of histone $\mathrm{H} 4$, and decrease HDAC2 activity and expression in these cells, and these effects are reversible by the antioxidant $N$-acetyl cysteine [34]. This mechanism may involve nitration of tyrosine residues in HDAC2 through the formation of peroxynitrite, which is generated through an interaction of superoxide anions and nitric oxide. A peroxynitrite-generating compound, 3-morpholinosydnonimine, causes a marked reduction in HDAC activity in epithelial cells in vitro [33]. The mechanism whereby tyrosine nitration leads to inactivation of HDAC2 is not yet certain. Nitration of proteins by peroxynitrite is now well documented to alter protein function, such as a reduction in enzymatic activity (fig. 4) [35]. It is possible that a tyrosine in the catalytic region of HDAC2 becomes nitrated, thus interfering with its enzymatic efficiency. Furthermore, nitration of proteins appears to make them more susceptible to protein degradation

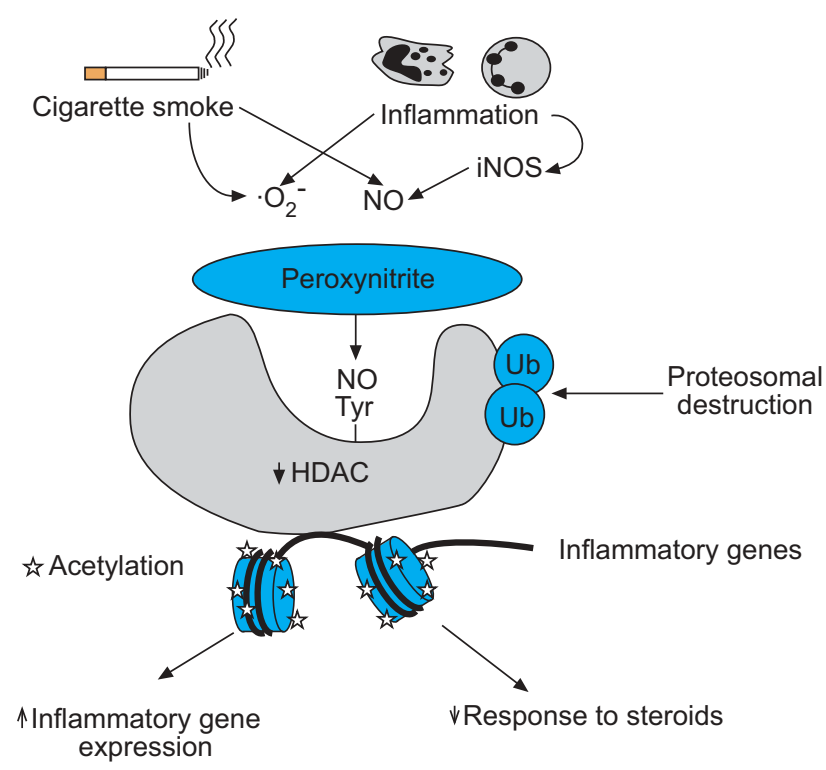

FIGURE 4. Possible mechanism of reduction in histone deacetylase (HDAC)2 HDAC2 is inactivated by peroxynitrite, generated by an interaction of nitric oxide (NO) generated by inducible NO synthase (iNOS) and cigarette smoke and superoxide anions $\left(\mathrm{O}_{2}{ }^{-}\right)$. Peroxynitrite nitrates tyrosine (Tyr) residues on HDAC2, and this may block enzymatic activity and also mark the enzyme for ubiquitination (Ub) and destruction by the proteasome. The loss of HDAC2 leads to amplification of the inflammatory response and resistance to corticosteroids. via the proteasome [36], which may explain the marked reduction in HDAC2 protein expression in severe COPD [27].

The effects of oxidative stress are mimicked by cigarette smoke extract and its effects are blocked by the antioxidant $N$-acetylcysteine [37]. This suggests that cigarette smoking may be one of the mechanisms inducing HDAC deficiency in COPD patients. There is considerable evidence for increased oxidative stress in the respiratory tract of patients with COPD, including increased concentrations of ethane and 8isoprostane, markers of oxidative stress, in exhaled breath, and 4-hydroxynonenal in the peripheral lungs of COPD patients [38-41]. These markers are increased to a greater extent in COPD patients than normal smokers and are related to disease severity. There is also evidence for increased markers of oxidative stress in ex-smokers, indicating that oxidative stress is likely to be generated by the ongoing inflammatory process in these patients, as well as active cigarette smoking. Oxidative stress is also increased in patients with severe asthma [42, 43], and this may result in reduced HDAC activity, as seen in COPD patients. Similarly, oxidative stress is increased in interstitial lung disease and cystic fibrosis [44-47].

\section{Virus infections}

Adenovirus infection increases the expression of inflammatory genes in epithelial cells in vitro, and this appears to be mediated via the adenoviral E1A protein, which is capable of interacting with HAT-containing coactivators, such as CBP [48]. In COPD lungs, there is evidence for latent adenovirus infection and increased expression of E1A protein, so this may be a mechanism for amplification of inflammation in COPD patients $[49,50]$. Interestingly, adenovirus infection in guinea pigs amplifies the inflammatory response to allergens [51] and is associated with a significant reduction in HDAC activity in the lungs of ovalbumin-sensitised animals [52]. Thus, the amplifying effects of adenovirus may be due to an inhibitory effect on HDAC, and it is possible that there is a molecular interaction between HDAC and E1A protein within the nucleus.

\section{CORTICOSTEROIDS AND HISTONE ACETYLATION}

Corticosteroids are by far the most effective therapy available for asthma, and inhaled steroids have revolutionised its management since the mid-1990s [53]. Inhaled steroids are not only effective in virtually all patients with asthma, but they are also almost free of systemic side-effects. In view of the complexity of inflammation in asthma, it has been difficult to understand how small doses of corticosteroids could be so effective in suppressing this inflammation, as so many inflammatory cells and mediators are involved in the pathophysiology of asthma. It is now becoming clear that the inflammation in asthma is largely driven by the increased expression of multiple inflammatory genes via the activation of proinflammatory transcription factors, such as AP-1 and NF- $\kappa$ B. This results in acetylation of core histones, as discussed earlier. Corticosteroids appear to suppress inflammation in asthma by switching off these inflammatory genes by targeting these transcription factors and their ability to induce histone modifications and chromatin remodelling $[54,55]$. 


\section{Gene activation by corticosteroids}

Corticosteroids cross the cell membrane and bind to glucocorticoid receptors (GR) in the cytoplasm, which rapidly translocate to the nucleus, where the activated GR may bind to glucocorticoid recognition elements (GRE) in the promoter region of steroid-sensitive genes. This results in the switching on of certain genes, including several anti-inflammatory genes. The activation of genes by relatively high concentrations of corticosteroids is associated with a selective acetylation of lysine residues 5 and 16 on histone $\mathrm{H} 4$, resulting in increased gene transcription (fig. 5) $[8,56]$. This is a different pattern from the acetylation of the N-terminal tail by inflammatory stimuli, which involves residues 8 and 12, as described previously. This acetylation pattern is correlated with increased secretion of the antiprotease, anti-inflammatory protein secretory leukoprotease inhibitor (SLPI), in response to corticosteroids in an epithelial cell line. Activated GR may bind to coactivator molecules, such as CBP or PCAF, as well as steroid-receptor coactivator-1 and glucocorticoid receptor interacting protein-1, which all possess $\mathrm{HAT}$ activity $[57,58]$.

Corticosteroids may suppress inflammation by increasing the synthesis of anti-inflammatory proteins, such as annexin-1 (lipocortin-1), SLPI, IL-10, the inhibitor of NF- $\kappa B$, I $\kappa \mathrm{B}-\alpha$, glucocorticoid-induced leucine zipper protein, which inhibits both NF- $\mathrm{B}$ and AP-1 $[8,59]$, and mitogen-activated protein (MAP) kinase phosphatase-1, which inhibits p38 MAP kinase [60]. However, it seems unlikely that the widespread antiinflammatory actions of corticosteroids could be explained by increased transcription of small numbers of anti-inflammatory genes, particularly as high concentrations of corticosteroids are

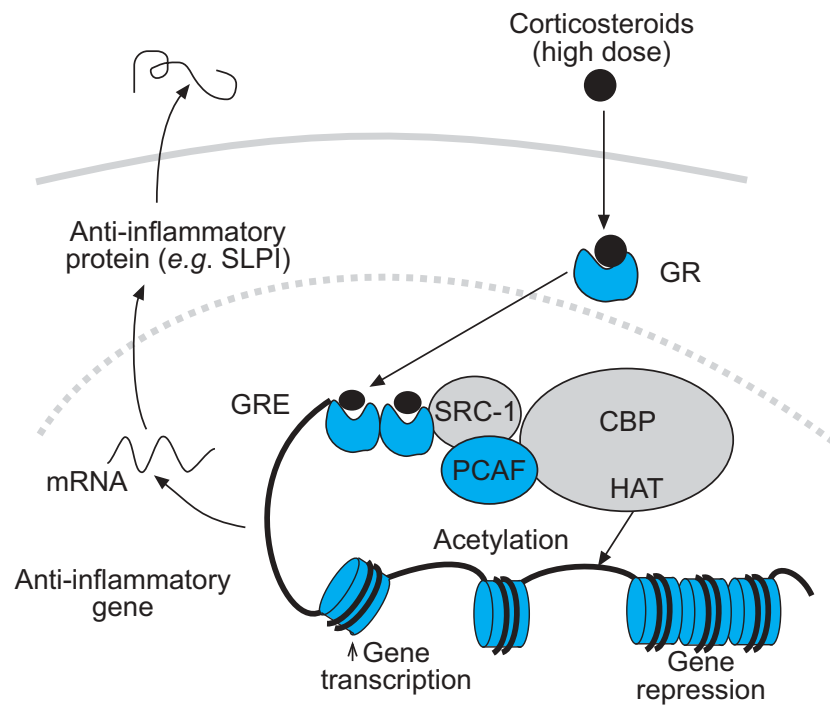

FIGURE 5. Gene activation by corticosteroids. Corticosteroids bind to cytoplasmic glucocorticoid receptors (GR), which translocate to the nucleus, where they bind to glucocorticoid response elements (GRE) in the promoter region of steroid-sensitive genes and also directly or indirectly to coactivator molecules, such as CREB-binding protein (CBP), p300/CBP activating factor (PCAF) or steroidreceptor coactivator (SRC)-1, which have intrinsic histone acetyltransferase (HAT) activity, causing acetylation of lysines on histone $\mathrm{H} 4$, which leads to activation of genes encoding anti-inflammatory proteins, such as secretory leukoprotease inhibitor (SLPI). usually required for these responses, whereas, in clinical practice, corticosteroids are able to suppress inflammation at low concentrations. It is also likely that many of the side-effects of corticosteroids are mediated by gene-activation mechanisms, as mice expressing a mutant form of GR that cannot dimerise and, thus, bind DNA lose the metabolic effects of corticosteroids, while retaining their anti-inflammatory effects, which are largely due to the interaction of GR monomers with $\mathrm{NF}-\kappa \mathrm{B}$ and associated coactivator proteins [61].

\section{Gene suppression by corticosteroids}

Most of the inflammatory genes that are activated in asthma do not have GRE sites in their promoter regions, yet are potently repressed by corticosteroids. It has become clear that most of the anti-inflammatory actions of corticosteroids are due to suppression of the actions of pro-inflammatory transcription factors, such as AP- 1 and NF- $\mathrm{kB}$, which regulate the expression of genes that code for many inflammatory proteins, such as cytokines, inflammatory enzymes, adhesion molecules and inflammatory receptors [1, 2]. The activated GR can interact directly with activated transcription factors by a proteinprotein interaction, which, in many cases, does not alter DNA binding. Thus, treatment of asthmatic patients with high doses of inhaled corticosteroids that suppress airway inflammation is not associated with any reduction in NF- $\kappa \mathrm{B}$ binding to DNA [62]. This suggests that corticosteroids are more likely to be acting downstream of the binding of pro-inflammatory transcription factors to DNA, and attention has now been focused on their effects on chromatin structure and histone acetylation.

Activated GR may directly bind to CBP or other coactivators to inhibit their HAT activity [8], thus preventing the subsequent histone acetylation and chromatin remodelling. More importantly, particularly at low concentrations that are likely to be relevant therapeutically in asthma treatment, activated GR recruits corepressor proteins, such as HDAC2, to the activated inflammatory gene transcriptional complex, resulting in deacetylation of histones and, thus, a decrease in inflammatory gene transcription (fig. 6) [8]. This mechanism can account for the clinical efficacy of corticosteroids in asthma, and GR may recruit HDAC2 to all inflammatory gene promoters that have been activated by NF- $\kappa \mathrm{B}$ and other proinflammatory transcription factors. Using a chromatin immunoprecipitation assay, it has been demonstrated that corticosteroids reverse the acetylation of the promoter of inflammatory genes, such as GM-CSF [8]. Other genes are not recognised through this mechanism, so corticosteroids do not switch off genes involved in basal cell functions, proliferation or survival. Furthermore, this explains why corticosteroids are relatively safe, as sideeffects may be mediated mainly by gene activation mechanisms, which require higher concentrations of corticosteroids, rather than via gene repression and HDAC recruitment.

\section{CORTICOSTEROID RESISTANCE}

Although corticosteroids are highly effective in the control of asthma and other chronic inflammatory or immune diseases, a small proportion of patients fail to respond even to high doses of oral corticosteroids [63-65], and patients with COPD are largely unresponsive to corticosteroids [66]. The recent recognition that histone acetylation and deacetylation are important in the mechanisms of action of corticosteroids has 


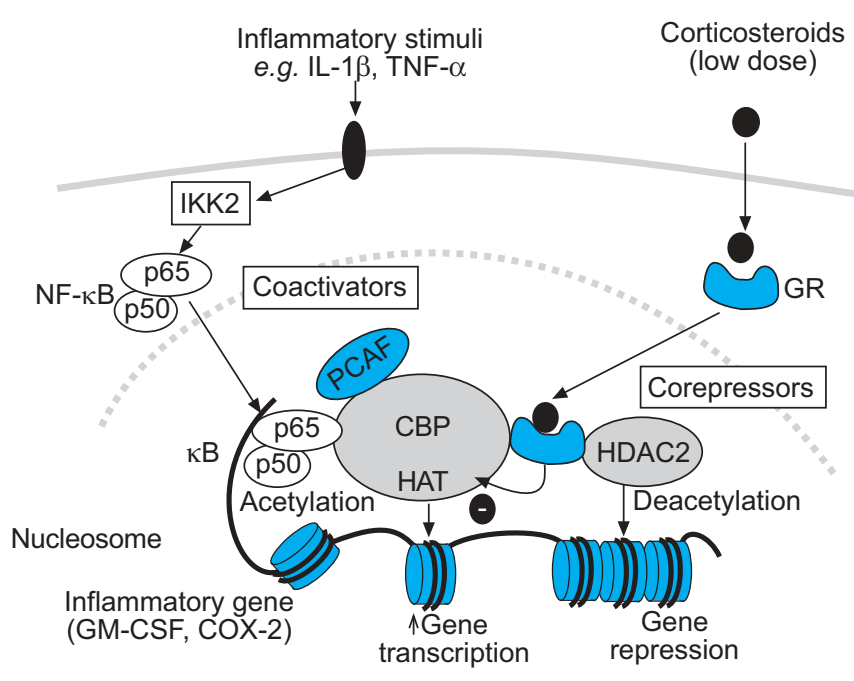

FIGURE 6. Inflammatory gene suppression by corticosteroids. Inflammatory genes are activated by inflammatory stimuli, such as interleukin (IL)-1 $\beta$ or tumour necrosis factor (TNF)- $\alpha$, resulting in activation of $\mathrm{I}-\mathrm{kB}$ kinase (IKK)2, which activates the transcription factor nuclear factor (NF)- $\mathrm{kB}$. A heterodimer composed of p50 and p65 NF-KB proteins translocates to the nucleus and binds to specific $\mathrm{KB}$ recognition sites and also to coactivators, such as CREB-binding protein (CBP) or p300/ CBP-activating factor (PCAF), which have intrinsic histone acetyltransferase (HAT) activity. This results in acetylation of lysines in core histone $\mathrm{H} 4$, resulting in increased expression of genes encoding inflammatory proteins, such as granulocyte-macrophage colony-stimulating factor (GM-CSF). After activation by corticosteroids, glucocorticoid receptors (GR) translocate to the nucleus and bind to coactivators to directly inhibit HAT activity, and histone deacetylases (HDAC) are recruited, thus resulting in histone acetylation reversal leading to the suppression of inflammatory genes. COX: cyclo-oxygenase.

provided novel molecular insights into molecular mechanisms of corticosteroid resistance.

\section{Asthma}

Corticosteroid-resistant patients, although uncommon, present considerable management problems $[55,65]$. It is likely that there is a spectrum of steroid responsiveness, with the rare resistance at one end, but a relative resistance is seen in patients who require high doses of inhaled and oral steroids (steroid-dependent asthma). Biopsy studies have demonstrated the typical eosinophilic inflammation of asthma in these patients.

There may be several mechanisms for resistance to the effects of corticosteroids, and these may differ between patients. It has been found that peripheral blood mononuclear cells from asthmatic patients who are steroid dependent or resistant show reduced suppression of cytokine release, as previously documented [67-69], but also show a reduction in acetylation of histone $\mathrm{H} 4$ in the nucleus following treatment of cells with a high concentration of dexamethasone $(1 \mu \mathrm{M})$. In one group of patients, nuclear localisation of GR in response to a high concentration of corticosteroids is impaired, and this accounts for the reduced histone acetylation, since there is a direct correlation between the degree of histone acetylation and the GR nuclear localisation [70]. This may be a result of GR nitrosylation leading to reduced dissociation of GR from heat shock protein-90 [71]. However, in another group of patients, the defect in acetylation of histone acetylation is found, despite normal nuclear localisation of GR. This may be a result of GR phosphorylation within the nucleus due to the activation of p38 MAP kinase, which may be activated by a combination of IL-2 and IL- 4 or by IL-13 alone [72], resulting in a failure to recruit distinct coactivator(s) (fig. 7). This may result in the failure of GR to transactivate steroid-responsive genes [73]. In this group of patients, specific acetylation of lysine 5 by corticosteroids is defective [70]. Presumably, this means that corticosteroids are not able to activate certain genes that are critical to the anti-inflammatory action of high doses of corticosteroids. Whether this is a genetic defect is not yet known.

\section{Chronic obstructive pulmonary disease}

Although inhaled corticosteroids are highly effective in asthma, they provide relatively little therapeutic benefit in COPD, despite the fact that active airway and lung inflammation are present. This may reflect the fact that the inflammation in COPD is not suppressed by corticosteroids, with no reduction in inflammatory cells, cytokines or proteases in induced sputum, even with oral corticosteroids [74-76]. Furthermore, histological analysis of the peripheral airways of patients with severe COPD shows an intense inflammatory response, despite treatment with high doses of inhaled corticosteroids [28]. There is some evidence that an active steroid-resistance mechanism exists in COPD, as corticosteroids fail to inhibit cytokines (such as IL- 8 and TNF- $\alpha$ ) that they normally suppress $[74,75]$. In vitro studies show that cytokine release from the alveolar macrophages of COPD patients is markedly resistant to the anti-inflammatory effects of corticosteroids compared with cells from normal smokers, and, in turn, these are more resistant than alveolar macrophages from nonsmokers [77, 78]. This lack of response to corticosteroids may be explained, at least in part, by an inhibitory effect of cigarette smoking and oxidative stress on HDAC function, thus interfering with the critical anti-inflammatory action of

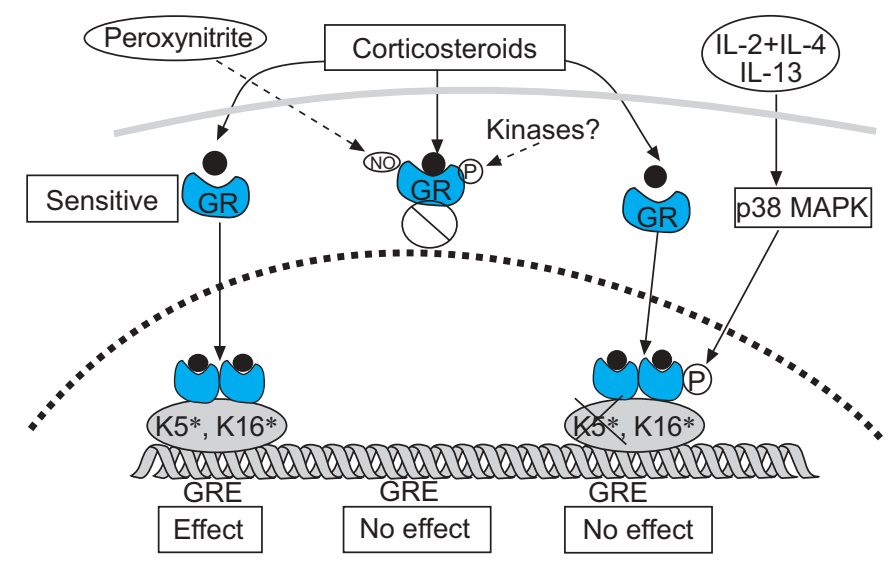

FIGURE 7. Possible mechanisms of corticosteroid resistance in asthma. In group 1 patients, cytokines such as interleukin (IL)-2, -4 and -13 induce p38 mitogen-activated protein kinase (MAPK), which phosphorylates glucocorticoid receptors (GR) in the cytoplasm, preventing their nuclear translocation. In group 2 patients, nuclear translocation of GR in response to corticosteroid therapy is normal, but there is a reduction in acetylation of lysine $(\mathrm{K}) 5$ of histone $\mathrm{H} 4$, presumably blocking the transcription of some important anti-inflammatory protein. NO: nitric oxide; GRE: glucocorticoid recognition elements. 
corticosteroids [30]. Indeed, there is a correlation between HDAC activity and the suppressive effects of a corticosteroid on cytokine release. It is likely that oxidative and nitrative stress in COPD specifically impairs HDAC2, as discussed earlier, resulting in corticosteroid resistance (fig. 8) [79]. Although this is seen in all stages of COPD, it is most marked in the patients with the most severe disease [27]. Even in patients with COPD who have stopped smoking, the steroid resistance persists [74, 75], and these patients are known to have continuing oxidative stress [39].

As oxidative stress is also increased in patients with severe asthma, and during exacerbations [43, 80,81], a reduction in HDAC may also account for the reduced responsiveness to corticosteroids in these patients.

\section{Smoking asthmatics}

As discussed previously, asthmatic patients who smoke have more severe disease and are also resistant to the antiinflammatory effects of corticosteroids [82, 83]. A plausible explanation for this steroid resistance is the combined effect of asthma and cigarette smoking on HDAC, resulting in a marked reduction comparable with that seen in COPD patients, and this is confirmed by the current authors' preliminary data [25].

\section{Virus infections}

As discussed earlier, adenovirus infection in guinea pigs appears to amplify the inflammatory response, but also induces corticosteroid resistance [84]. The steroid resistance

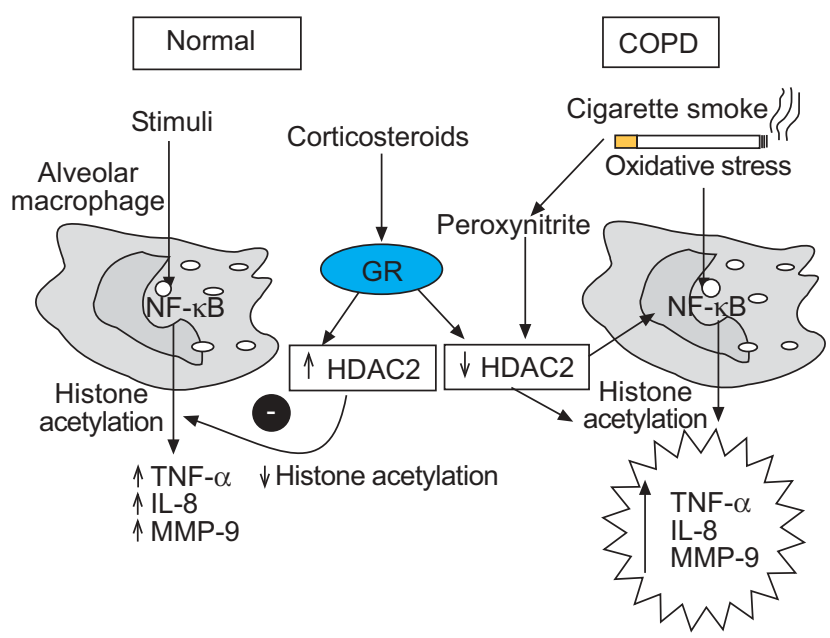

FIGURE 8. Proposed mechanism of corticosteroid resistance in chronic obstructive pulmonary disease (COPD) patients. Stimulation of normal alveolar macrophages activates nuclear factor (NF)-kB and other transcription factors to switch on histone acetyltransferase, leading to histone acetylation and, subsequently, to the transcription of genes encoding inflammatory proteins, such as tumour necrosis factor (TNF)- $\alpha$, interleukin (IL)-8 and matrix metalloproteinase (MMP)-9. Corticosteroids reverse this by binding to glucocorticoid receptors (GR) and recruiting histone deacetylase (HDAC)2. This reverses the histone acetylation induced by NF-KB and switches off the activated inflammatory genes. In COPD patients, cigarette smoke activates macrophages, as in normal subjects, but oxidative stress (acting through the formation of peroxynitrite) impairs the activity of HDAC2. This amplifies the inflammatory response to NF-kB activation, but also reduces the anti-inflammatory effect of corticosteroids, as HDAC2 is now unable to reverse histone acetylation. may be explained by the reduction in HDAC activity of virusinfected animals [52]. Therefore, the latent adenovirus infections described in COPD may contribute to the reduction in HDAC activity described in the peripheral lungs of these patients. Persistence of adenovirus infections has also been implicated in steroid resistance in children with asthma [85]. Other viral infections may also impair the action of HDAC2 and, thus, induce steroid resistance, but this still needs to be explored.

\section{Other diseases}

In cystic fibrosis and interstitial lung disease, the high level of oxidative stress [44-47] may impair HDAC2 activity and also account for the poor response to corticosteroid in these diseases [86, 87].

\section{EFFECTS OF DRUGS Corticosteroids}

As indicated previously, corticosteroids inhibit HAT activity and enable HDAC2 to be recruited to NF- $\kappa B$, thus switching off activated inflammatory genes. These interactions involve direct or indirect binding of GR with CBP and HDAC [56]. This suggests that it may be possible to develop dissociated steroids that discriminate between the DNA binding of GR, which requires receptor dimerisation, and the interaction with inflammatory gene complexes, which does not require this. Several dissociated steroids are in development with a view to reducing systemic side-effects, which are largely due to DNA binding, and anti-inflammatory effects, which are due to protein-protein interaction [88]. Long-term treatment with high concentrations of corticosteroids can also lead to enhanced HDAC2 expression [8].

\section{Theophylline}

Theophylline has been used to treat asthma for many years, but its mechanism of action has been difficult to elucidate. Originally, theophylline was used as a bronchodilator, and it relaxes airway smooth muscle by inhibiting phosphodiesterases (PDE). There is accumulating evidence that theophylline has anti-inflammatory effects at lower doses, but it is unlikely that these are mediated by PDE inhibition, as the inhibition of these enzymes is trivial at low plasma concentrations that are clinically effective [89]. It has been shown that the anti-inflammatory effects of theophylline may be mediated via activation of HDAC, and that this effect is independent of PDE inhibition [90]. Low doses of theophylline significantly increase HDAC activity in bronchial biopsies from asthmatic patients, and the increase in HDAC activity is correlated with the reduction in airway eosinophils [90]. Theophylline is active in low concentrations $\left(10^{-7}-10^{-5} \mathrm{M}\right)$ on nuclear extracts, indicating that it works within the nucleus and does not require surface receptors. This appears to be a novel mechanism of theophylline and is not mimicked by PDE inhibitors or by adenosine receptor antagonists [90]. This is of particular importance, as the major side-effects of theophylline are mediated via PDE inhibition (nausea, headaches) and adenosine receptor $\left(A_{1}\right)$ antagonism (cardiac arrhythmias, seizures). Theophylline appears to preferentially activate class I HDACs, including HDAC2 [15]. However, the exact mechanism whereby theophylline activates HDAC is not yet certain, but is likely to be through signal transduction pathways (probably 
kinases) that regulate HDAC activity. The effects of theophylline on HDAC appear to be enhanced under conditions of oxidative stress, making it more efficient as a regulator of inflammatory genes [15]. This means that the dose of theophylline does not have to be increased as the disease becomes more severe, as the increase in oxidative stress would increase drug activity.

This predicts that theophylline will enhance the antiinflammatory actions of corticosteroids, as the HDAC2 recruited to the activated p65 complex at the promoters of inflammatory genes will be more effective at switching off these genes. Indeed, therapeutic concentrations of theophylline markedly potentiate the anti-inflammatory effects of corticosteroids in vitro [90]. This may explain why adding a low dose of theophylline is more effective than increasing the dose of inhaled corticosteroids in patients who are not controlled adequately [91-93].

In COPD macrophages, HDAC activity is reduced and associated with increased inflammatory gene expression and steroid resistance. Low concentrations of theophylline are able to restore HDAC activity in these macrophages, and this results in increased steroid responsiveness in these cells [15]. These in vitro studies suggest that low doses of theophylline may have the capacity to reverse steroid resistance in COPD patients, and trials are now underway to test this idea. Indeed, in COPD patients, low-dose theophylline has an anti-inflammatory effect, in contrast with the lack of response to high doses of corticosteroids [94], and it is possible that there is an interaction between theophylline and endogenous cortisol. Furthermore, since similar mechanisms of steroid resistance may also apply in severe asthma and smoking asthmatics, theophylline may also be useful in these patients, and this may explain why theophylline appears to be useful as an add-on therapy to inhaled steroids, particularly in patients with severe disease [95].

\section{THERAPEUTIC IMPLICATIONS AND FUTURE DIRECTIONS}

The recognition that histone acetylation status regulates inflammatory gene expression has improved the understanding of chronic inflammatory lung diseases, and the discovery that oxidative and nitrative stress can lead to amplified inflammation and corticosteroid resistance in COPD patients, and probably severe asthma and smoking asthmatic patients, may have important clinical implications.

\section{Novel corticosteroids}

Currently available inhaled corticosteroids are absorbed from the lungs into the systemic circulation, and, therefore, at high doses, they have systemic effects. Therefore, there is a search for safer steroids with reduced systemic effects. The major task in developing these drugs is to dissociate the antiinflammatory effects from the endocrine actions that are associated with side-effects. This may be possible, since most of the anti-inflammatory actions of corticosteroids are mediated by gene repression as a consequence of histone deacetylation following the recruitment of HDAC2 to activated inflammatory genes. By contrast, the endocrine and metabolic effects of steroids that are responsible for the systemic sideeffects of corticosteroids are likely to be mediated predominantly via genomic actions of corticosteroids involving DNA binding and histone acetylation. A separation of transactivation and transrepression has been demonstrated using reporter gene constructs in transfected cells, using selective mutations of the glucocorticoid receptor $[96,97]$. In addition, in mice with GR that do not dimerise and cannot bind to DNA, there is no transactivation, but transrepression appears to be normal [61, 98]. The topical steroids currently used in asthma therapy, such as fluticasone propionate and budesonide, appear to have more potent transrepression than transactivation effects, which may account for their selection as potent anti-inflammatory agents [99]. Novel steroids have been described, in which there is potent transrepression with relatively little transactivation, which may have a greater therapeutic ratio [88]. The recent resolution of the crystal structure for the ligand-binding domain of GR may help in the better design of dissociated steroids [100].

\section{Nonsteroidal steroids}

Now that the molecular mechanisms of corticosteroids have been elucidated, this raises the possibility that novel nonsteroidal anti-inflammatory treatments might be developed, which mimic the actions of corticosteroids on inflammatory gene regulation. The mechanism by which GR interacts with HAT and HDAC is not yet fully understood. It is likely that several other interacting proteins may be involved, which might be targets for the development of new drugs.

\section{New theophylline derivatives}

Other means of activating HDACs may have therapeutic potential, and theophylline represents the first drug that has been shown to have this property, resulting in the marked potentiation of the anti-inflammatory effects of corticosteroids. It may be possible to discover other drugs in this class, which could form the basis of a new class of anti-inflammatory drugs without the side-effects that limit the use of theophylline [89]. While low concentrations of theophylline activate HDAC, higher concentrations $\left(>10^{-4} \mathrm{M}\right)$ inhibit HDAC. This may be an indication that theophylline is a partial agonist, and a search for fuller agonists might lead to more effective HDAC activators. Novel HDAC activators might be discovered by high throughput screening using HDAC activation, particularly under conditions of oxidative stress. Kinases or phosphatases that regulate HDAC2 activity in a similar manner to theophylline may also prove to be effective add-on therapies to corticosteroids.

Many of the anti-inflammatory effects of corticosteroids appear to be mediated via inhibition of the transcriptional effects of $\mathrm{NF}-\kappa \mathrm{B}$, and, currently, small molecule inhibitors of I $\kappa \mathrm{B}$ kinase (IKK)2, which activate NF- $\kappa B$, are in development. However, corticosteroids have additional effects, so it is not certain whether IKK2 inhibitors will parallel the clinical effectiveness of corticosteroids, and they may have side-effects, such as increased susceptibility to infections.

Treatments that bypass or reverse steroid resistance are also needed. p38 MAP kinase inhibitors might reduce steroid resistance and act as anti-inflammatory treatments in patients with some forms of steroid-resistant asthma, but would not be expected to benefit the patients with the form of steroid resistance associated with a defect in acetylation of lysine 5 on histone H4. In COPD patients, there is an urgent need to 
develop novel anti-inflammatory treatments or to reverse corticosteroid resistance [101]. Low-dose theophylline, by increasing HDAC activity, may also reverse corticosteroid resistance in patients with COPD [102].

\section{Antioxidants}

Since oxidative stress is a mechanism that may impair HDAC activity and expression, as seen in COPD and severe asthma, antioxidants have the potential to increase HDAC activity, switch off inflammatory genes and restore steroid responsiveness [32]. Currently available antioxidants, such as $N$-acetyl cysteine, are not very potent and may not sufficiently reduce oxidative stress in the lungs. New, more potent antioxidants are needed in the future, and there are several drugs in development, including new glutathione and superoxide dismutase analogues [103].

\section{Inducible nitric oxide synthase inhibitors}

Peroxynitrite, formed by an interaction of superoxide anions and nitric oxide (NO), may lead to a reduction in HDAC activity and expression. NO is derived predominantly from inducible NO synthase (iNOS), and this suggests that inhibition of iNOS may block the formation of peroxynitrite and reverse steroid resistance. Several selective iNOS inhibitors are now in development, and one of these has been shown to markedly reduce NO formation in asthmatic patients [104].

\section{Molecular genetics}

It is likely that gene polymorphisms predispose to the development of COPD in certain smokers and severe asthma, but the genes for COPD susceptibility and asthma severity are not well defined. Little is known about the single nucleotide polymorphisms of HATs and HDACs, but this is likely to be a fruitful area for research in the future.

\section{Future research}

Research into the role of histone acetylation and deacetylation in disease is only in its infancy. Most research in this field has focused on cancer and cell differentiation, but this review highlights its applicability to understanding chronic inflammatory diseases and the mechanism of action of currently available therapies. Histone acetylation and deacetylation are influenced by many factors (table 1). New techniques, such as interference RNA, can knock down specific HATs and HDACs in order to study their role and interaction in pulmonary cells. This approach may also be applicable in animal models in vivo. In mice, selective deletion and transgenic expression of specific HAT and HDAC genes is also likely to be very informative, particularly when conditional knockouts in selective cell types are developed. There are currently few selective drugs available, but nonselective HDAC inhibitors, such as TSA and suberoylanilide hydroxamic acid, are already being used to study global HDAC reduction. More selective inhibitors are now emerging and may be useful as exploratory tools [105]. Theophylline is the only HDAC activator to be identified so far, but the molecular mechanisms of this action remain to be determined. Understanding the molecular pathways whereby theophylline activates HDACs may lead to novel therapeutic approaches for treating inflammatory diseases in the future.

An important emerging area of research is how different modifications of core histones, such as phosphorylation,

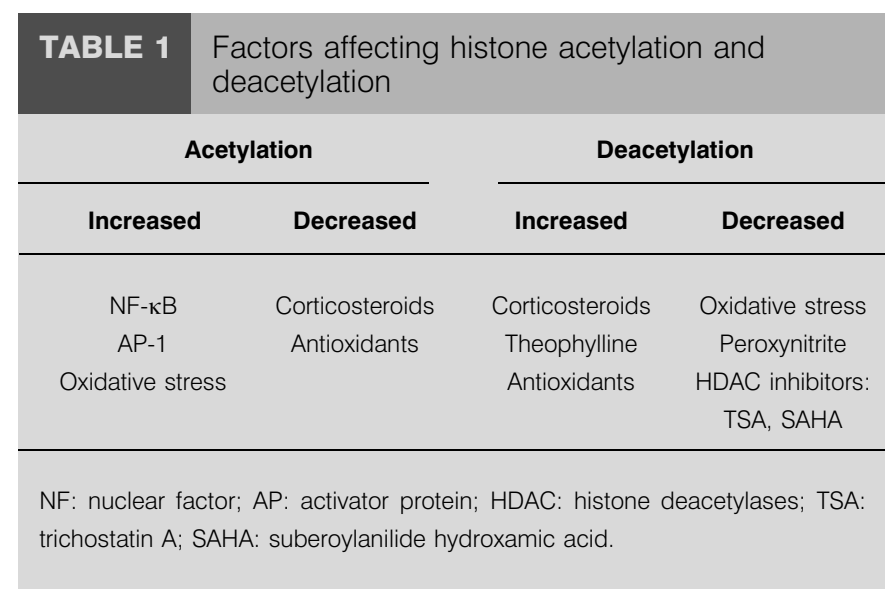

methylation and ubiquitination, interact with acetylation to determine the specificity and kinetics of specific gene expression. This may lead to a better understanding of how genes are differentially regulated and how more specific gene regulation might be produced in the future. A further new area of research concerns the recognition that HATs and HDACs may modify proteins other than histones, including transcription factors and key regulatory proteins [106-108]. This is likely to be of major importance in disease and extends the perspective of HATs and HDACs.

The study of histone acetylation and deacetylation is a rapidly growing area of research, particularly as new technologies are developed. This research has already led to important new insights into the basic mechanisms involved in asthma and chronic obstructive pulmonary disease. The implications for future research into pulmonary diseases are likely to be profound.

\section{REFERENCES}

1 Barnes PJ, Adcock IM. Transcription factors and asthma. Eur Respir J 1998; 12: 221-234.

2 Barnes PJ, Karin M. Nuclear factor-кB: a pivotal transcription factor in chronic inflammatory diseases. New Engl J Med 1997; 336: 1066-1071.

3 Wright JG, Christman JW. The role of nuclear factor $\kappa \mathrm{B}$ in the pathogenesis of pulmonary diseases: implications for therapy. Am J Respir Med 2003; 2: 211-219.

4 Littau VC, Burdick CJ, Allfrey VG, Mirsky SA. The role of histones in the maintenance of chromatin structure. Proc Natl Acad Sci USA 1965; 54: 1204-1212.

5 Ogryzko VV, Schiltz RL, Russanova V, Howard BH, Nakatani Y. The transcriptional coactivators p300 and CBP are histone acetyltransferases. Cell 1996; 87: 953-959.

6 Roth SY, Denu JM, Allis CD. Histone acetyltransferases. Annu Rev Biochem 2001; 70: 81-120.

7 Gao L, Cueto MA, Asselbergs F, Atadja P. Cloning and functional characterization of HDAC11, a novel member of the human histone deacetylase family. J Biol Chem 2002; 277: 25748-25755.

8 Ito K, Barnes PJ, Adcock IM. Glucocorticoid receptor recruitment of histone deacetylase 2 inhibits IL-1 $\beta$ induced histone $\mathrm{H} 4$ acetylation on lysines 8 and 12. Mol Cell Biol 2000; 20: 6891-6903. 
9 de Ruijter AJ, van Gennip AH, Caron HN, Kemp S, van Kuilenburg AB. Histone deacetylases (HDACs): characterization of the classical HDAC family. Biochem J 2003; 370: 737-749.

10 Thiagalingam S, Cheng $\mathrm{KH}$, Lee HJ, Mineva N, Thiagalingam A, Ponte JF. Histone deacetylases: unique players in shaping the epigenetic histone code. Ann N Y Acad Sci 2003; 983: 84-100.

11 Peterson CL. HDAC's at work: everyone doing their part. Mol Cell 2002; 9: 921-922.

12 Jones PL, Shi YB. N-CoR-HDAC corepressor complexes: roles in transcriptional regulation by nuclear hormone receptors. Curr Top Microbiol Immunol 2003; 274: 237-268.

13 Fernandes I, Bastien Y, Wai T, et al. Ligand-dependent nuclear receptor corepressor LCoR functions by histone deacetylase-dependent and -independent mechanisms. Mol Cell 2003; 11: 139-150.

14 Yoshida M, Matsuyama A, Komatsu Y, Nishino N. From discovery to the coming generation of histone deacetylase inhibitors. Curr Med Chem 2003; 10: 2351-2358.

15 Cosio BG, Tsaprouni L, Ito K, Jazrawi E, Adcock IM, Barnes PJ. Theophylline restores histone deacetylase activity and steroid responses in COPD macrophages. J Exp Med 2004; 200: 689-695.

16 Tomita K, Barnes PJ, Adcock IM. The effect of oxidative stress on histone acetylation and IL-8 release. Biochem Biophys Res Commun 2003; 301: 572-577.

17 Ashburner BP, Westerheide SD, Baldwin AS Jr. The p65 (RelA) subunit of NF- $\kappa$ B interacts with the histone deacetylase (HDAC) corepressors HDAC1 and HDAC2 to negatively regulate gene expression. Mol Cell Biol 2001; 21: 7065-7077.

18 Chen L, Fischle W, Verdin E, Greene WC. Duration of nuclear NF- $\kappa \mathrm{B}$ action regulated by reversible acetylation. Science 2001; 293: 1653-1657.

19 Zhong H, May MJ, Jimi E, Ghosh S. The phosphorylation status of nuclear NF- $\mathrm{BB}$ determines its association with CBP/p300 or HDAC-1. Mol Cell 2002; 9: 625-636.

20 Cohen HY, Miller C, Bitterman KJ, et al. Calorie restriction promotes mammalian cell survival by inducing the SIRT1 deacetylase. Science 2004; 305: 390-392.

21 Buck SW, Gallo CM, Smith JS. Diversity in the Sir2 family of protein deacetylases. J Leukoc Biol 2004; 75: 939-950.

22 Yeung F, Hoberg JE, Ramsey CS, et al. Modulation of NFkappaB-dependent transcription and cell survival by the SIRT1 deacetylase. EMBO J 2004; 23: 2369-2380.

23 Ito K, Caramori G, Lim S, et al. Expression and activity of histone deacetylases (HDACs) in human asthmatic airways. Am J Respir Crit Care Med 2002; 166: 392-396.

24 Cosio BG, Mann B, Ito K, et al. Histone acetylase and deacetylase activity in alveolar macrophages and blood monocytes in asthma. Am J Respir Crit Care Med 2004; 170: 141-147.

25 Murahidy A, Ito M, Adcock IM, Barnes PJ, Ito K. Reduction of histone deacetylase expression and activity in smoking asthmatics. Am J Respir Crit Care Med 2005; (In press).

26 Thomson NC, Chaudhuri R, Livingston E. Active cigarette smoking and asthma. Clin Exp Allergy 2003; 33: 1471-1475.
27 To Y, Elliott WM, Ito M, et al. Total histone deacetylase activity decreases with increasing clinical stage of COPD. Am J Respir Crit Care Med 2004; 169: A276.

28 Hogg JC, Chu F, Utokaparch S, et al. The nature of smallairway obstruction in chronic obstructive pulmonary disease. New Engl J Med 2004; 350: 2645-2653.

29 Marwick JA, Kirkham PA, Stevenson CS, et al. Cigarette smoke alters chromatin remodelling and induces proinflammatory genes in rat lungs. Am J Respir Cell Mol Biol 2004; 31: 633-642.

30 Ito K, Lim S, Caramori G, Chung KF, Barnes PJ, Adcock IM. Cigarette smoking reduces histone deacetylase 2 expression, enhances cytokine expression and inhibits glucocorticoid actions in alveolar macrophages. FASEB J 2001; 15: 1100-1102.

31 Rahman I, Gilmour PS, Jimenez LA, Macnee W. Oxidative stress and TNF-alpha induce histone acetylation and NF-kappab/AP-1 activation in alveolar epithelial cells: potential mechanism in gene transcription in lung inflammation. Mol Cell Biochem 2002; 234-235: 239-248.

32 Rahman I, Marwick J, Kirkham P. Redox modulation of chromatin remodeling: impact on histone acetylation and deacetylation, NF- $\mathrm{kB}$ and pro-inflammatory gene expression. Biochem Pharmacol 2004; 68: 1255-1267.

33 Ito K, Tomita T, Barnes PJ, Adcock IM. Oxidative stress reduces histone deacetylase (HDAC)2 activity and enhances IL-8 gene expression: role of tyrosine nitration. Biochem Biophys Res Commun 2004; 315: 240-245.

34 Moodie FM, Marwick JA, Anderson CS, et al. Oxidative stress and cigarette smoke alter chromatin remodeling but differentially regulate NF-kappaB activation and proinflammatory cytokine release in alveolar epithelial cells. FASEB J 2004; 18: 1897-1899.

35 Schmidt P, Youhnovski N, Daiber A, et al. Specific nitration at tyrosine 430 revealed by high resolution mass spectrometry as basis for redox regulation of bovine prostacyclin synthase. J Biol Chem 2003; 278: 12813-12819.

36 Buchczyk DP, Grune T, Sies H, Klotz LO. Modifications of glyceraldehyde-3-phosphate dehydrogenase induced by increasing concentrations of peroxynitrite: early recognition by 20 S proteasome. Biol Chem 2003; 384: 237-241.

37 Cosio BG, Jazrawi E, Ito K, Barnes PJ, Adcock IM. Cigarette smoke decreases steroid responsiveness in monocytes: the role of histone deacetylase. Am J Respir Crit Care Med 2003; 167: A804.

38 Paredi P, Kharitonov SA, Leak D, Ward S, Cramer D, Barnes PJ. Exhaled ethane, a marker of lipid peroxidation, is elevated in chronic obstructive pulmonary disease. Am J Respir Crit Care Med 2000; 162: 369-373.

39 Montuschi P, Collins JV, Ciabattoni G, et al. Exhaled 8isoprostane as an in vivo biomarker of lung oxidative stress in patients with COPD and healthy smokers. Am J Respir Crit Care Med 2000; 162: 1175-1177.

40 Biernacki WA, Kharitonov SA, Barnes PJ. Increased leukotriene B4 and 8-isoprostane in exhaled breath condensate of patients with exacerbations of COPD Thorax 2003; 58: 294-298.

41 Rahman I, van Schadewijk AA, Crowther AJ, et al. 4Hydroxy-2-nonenal, a specific lipid peroxidation product, is elevated in lungs of patients with chronic 
obstructive pulmonary disease. Am J Respir Crit Care Med 2002; 166: 490-495.

42 Paredi P, Kharitonov SA, Barnes PJ. Elevation of exhaled ethane concentration in asthma. Am J Respir Crit Care Med 2000; 162: 1450-1454.

43 Montuschi P, Ciabattoni G, Corradi M, et al. Increased 8isoprostane, a marker of oxidative stress, in exhaled condensates of asthmatic patients. Am J Respir Crit Care Med 1999; 160: 216-220.

44 Montuschi P, Toni GC, Paredi P, et al. 8-isoprostane as a biomarker of oxidative stress in interstitial lung diseases. Am J Respir Crit Care Med 1998; 158: 1524-1527.

45 Montuschi P, Kharitonov SA, Ciabattoni G, et al. Exhaled 8-isoprostane as a new non-invasive biomarker of oxidative stress in cystic fibrosis. Thorax 2000; 55: 205-209.

46 Paredi P, Kharitonov SA, Leak D, et al. Exhaled ethane is elevated in cystic fibrosis and correlates with carbon monoxide levels and airway obstruction. Am J Respir Crit Care Med 2000; 161: 1247-1251.

47 Antuni JD, Kharitonov SA, Hughes D, Hodson ME, Barnes PJ. Increase in exhaled carbon monoxide during exacerbations of cystic fibrosis. Thorax 2000; 55: 138-142.

48 Higashimoto $\mathrm{Y}$, Elliott WM, Behzad AR, et al. Inflammatory mediator mRNA expression by adenovirus E1Atransfected bronchial epithelial cells. Am J Respir Crit Care Med 2002; 166: 200-207.

49 Retamales I, Elliott WM, Meshi B, et al. Amplification of inflammation in emphysema and its association with latent adenoviral infection. Am J Respir Crit Care Med 2001; 164: 469-473.

50 Hogg JC. Role of latent viral infections in chronic obstructive pulmonary disease and asthma. Am J Respir Crit Care Med 2001; 164: S71-S75.

51 Yamada K, Elliott WM, Hayashi S, Brattsand R, Hogg JC, Vitalis TZ. The effect of latent adenoviral infection on steroid suppression of allergic lung inflammation in guinea pigs. Am J Respir Crit Care Med 1999; 157: A516.

52 Ito M, Yamada K, Vitalis TZ, et al. Latent adenovirus infection decreases histone deacetylase activity in the lungs of ovalbumen-sensitized guinea pigs. Am J Respir Crit Care Med 2004; 169: A78.

53 Barnes PJ, Pedersen S, Busse WW. Efficacy and safety of inhaled corticosteroids. New developments. Am J Respir Crit Care Med 1998; 157: S1-S53.

54 Barnes PJ, Adcock IM. How do corticosteroids work in asthma? Ann Intern Med 2003; 139: 359-370.

55 Leung DY, Bloom JW. Update on glucocorticoid action and resistance. J Allergy Clin Immunol 2003; 111: 3-22.

56 Ito K, Jazrawi E, Cosio B, Barnes PJ, Adcock IM. p65activated histone acetyltransferase activity is repressed by glucocorticoids: mifepristone fails to recruit HDAC2 to the p65/HAT complex. J Biol Chem 2001; 276: 30208-30215.

57 Yao TP, Ku G, Zhou N, Scully R, Livingston DM. The nuclear hormone receptor coactivator SRC-1 is a specific target of p300. Proc Natl Acad Sci USA 1996; 93: 10626-10631.

58 Kurihara I, Shibata H, Suzuki T, et al. Expression and regulation of nuclear receptor coactivators in glucocorticoid action. Mol Cell Endocrinol 2002; 189: 181-189.
59 Mittelstadt PR, Ashwell JD. Inhibition of AP-1 by the glucocorticoid-inducible protein GILZ. J Biol Chem 2001; 276: 29603-29610.

60 Lasa M, Abraham SM, Boucheron C, Saklatvala J, Clark AR. Dexamethasone causes sustained expression of mitogen-activated protein kinase (MAPK) phosphatase 1 and phosphatase-mediated inhibition of MAPK p38. Mol Cell Biol 2002; 22: 7802-7811.

61 Reichardt HM, Tuckermann JP, Gottlicher M, et al. Repression of inflammatory responses in the absence of DNA binding by the glucocorticoid receptor. EMBO J 2001; 20: 7168-7173.

62 Hart L, Lim S, Adcock I, Barnes PJ, Chung KF. Effects of inhaled corticosteroid therapy on expression and DNAbinding activity of nuclear factor $-\kappa \mathrm{B}$ in asthma. $A m \mathrm{~J}$ Respir Crit Care Med 2000; 161: 224-231.

63 Szefler SJ, Leung DY. Glucocorticoid-resistant asthma: pathogenesis and clinical implications for management. Eur Respir J 1997; 10: 1640-1647.

64 Barnes PJ. Steroid-resistant asthma. Eur Respir Rev 2000; 10: 74-78.

65 Adcock IM, Lane SJ. Corticosteroid-insensitive asthma: molecular mechanisms. J Endocrinol 2003; 178: 347-355.

66 Barnes PJ. Inhaled corticosteroids are not helpful in chronic obstructive pulmonary disease. Am J Respir Crit Care Med 2000; 161: 342-344.

67 Corrigan C, Brown PH, Barnes NC, et al. Glucocorticoid resistance in chronic asthma: glucocorticoid pharmacokinetics, glucocorticoid receptor characteristics and inhibition of peripheral blood $\mathrm{T}$ cell proliferation by glucocorticoids in vitro. Am Rev Respir Dis 1991; 144: 1016-1025.

68 Wilkinson JRW, Lane SJ, Lee TH. The effects of corticosteroids on cytokine generation and expression of activation antigens by monocytes in bronchial asthma. Int Arch Allergy Clin Immunol 1991; 94: 220-221.

69 Adcock IM, Lane SJ, Brown CA, Lee TH, Barnes PJ. Abnormal glucocorticoid receptor/AP-1 interaction in steroid-resistant asthma. J Exp Med 1995; 182: 1951-1958.

70 Matthews JG, Ito K, Barnes PJ, Adcock IM. Defective glucocorticoid receptor nuclear translocation and altered histone acetylation patterns in glucocorticoid-resistant patients. J Allergy Clin Immunol 2004; 113: 1100-1108.

71 Galigniana MD, Piwien-Pilipuk G, Assreuy J. Inhibition of glucocorticoid receptor binding by nitric oxide. Mol Pharmacol 1999; 55: 317-323.

72 Irusen E, Matthews JG, Takahashi A, Barnes PJ, Chung KF, Adcock IM. p38 Mitogen-activated protein kinase-induced glucocorticoid receptor phosphorylation reduces its activity: role in steroid-insensitive asthma. J Allergy Clin Immunol 2002; 109: 649-657.

73 Szatmary Z, Garabedian MJ, Vilcek J. Inhibition of glucocorticoid receptor-mediated transcriptional activation by p38 mitogen-activated protein (MAP) kinase. J Biol Chem 2004; 279: 43708-43715.

74 Keatings VM, Jatakanon A, Worsdell YM, Barnes PJ. Effects of inhaled and oral glucocorticoids on inflammatory indices in asthma and COPD. Am J Respir Crit Care Med 1997; 155: 542-548.

75 Culpitt SV, Nightingale JA, Barnes PJ. Effect of high dose inhaled steroid on cells, cytokines and proteases in 
induced sputum in chronic obstructive pulmonary disease. Am J Respir Crit Care Med 1999; 160: 1635-1639.

76 Loppow D, Schleiss MB, Kanniess F, Taube C, Jorres RA, Magnussen $\mathrm{H}$. In patients with chronic bronchitis a four week trial with inhaled steroids does not attenuate airway inflammation. Respir Med 2001; 95: 115-121.

77 Culpitt SV, Rogers DF, Shah P, et al. Impaired inhibition by dexamethasone of cytokine release by alveolar macrophages from patients with chronic obstructive pulmonary disease. Am J Respir Crit Care Med 2003; 167: 24-31.

78 Lim S, Roche N, Oliver BG, Mattos W, Barnes PJ, Fan CK. Balance of matrix metalloprotease- 9 and tissue inhibitor of metalloprotease-1 from alveolar macrophages in cigarette smokers. Regulation by interleukin-10. Am J Respir Crit Care Med 2000; 162: 1355-1360.

79 Barnes PJ, Ito K, Adcock IM. A mechanism of corticosteroid resistance in COPD: inactivation of histone deacetylase. Lancet 2004; 363: 731-733.

80 Baraldi E, Carraro S, Alinovi R, et al. Cysteinyl leukotrienes and 8-isoprostane in exhaled breath condensate of children with asthma exacerbations. Thorax 2003; 58: 505-509.

81 Caramori G, Papi A. Oxidants and asthma. Thorax 2004; 59: 170-173.

82 Chalmers GW, Macleod KJ, Thomson L, Little SA, McSharry C, Thomson NC. Smoking and airway inflammation in patients with mild asthma. Chest 2001; 120: 1917-1922.

83 Chaudhuri R, Livingston E, McMahon AD, Thomson L, Borland W, Thomson NC. Cigarette smoking impairs the therapeutic response to oral corticosteroids in chronic asthma. Am J Respir Crit Care Med 2003; 168: 1265-1266.

84 Yamada K, Elliott WM, Brattsand R, Valeur A, Hogg JC, Hayashi S. Molecular mechanisms of decreased steroid responsiveness induced by latent adenoviral infection in allergic lung inflammation. J Allergy Clin Immunol 2002; 109: $35-42$.

85 Macek V, Soru J, Korpriva S, Marin J. Persistent adenoviral infection and chronic airway obstruction in children. Am J Respir Crit Care Med 1994; 150: 7-10.

86 Dezateux C, Walters S, Balfour-Lynn I. Inhaled corticosteroids for cystic fibrosis. Cochrane Database Syst Rev 2000; 2: CD001915.

87 Richeldi L, Davies HR, Ferrara G, Franco F. Corticosteroids for idiopathic pulmonary fibrosis. Cochrane Database Syst Rev 2003; 3: CD002880.

88 Schacke H, Schottelius A, Docke WD, et al. Dissociation of transactivation from transrepression by a selective glucocorticoid receptor agonist leads to separation of therapeutic effects from side effects. Proc Natl Acad Sci USA 2004; 101: 227-232.

89 Barnes PJ. Theophylline: new perspectives on an old drug. Am J Respir Crit Care Med 2003; 167: 813-818.

90 Ito K, Lim S, Caramori G, et al. A molecular mechanism of action of theophylline: induction of histone deacetylase activity to decrease inflammatory gene expression. Proc Natl Acad Sci USA 2002; 99: 8921-8926.

91 Evans DJ, Taylor DA, Zetterstrom O, Chung KF, O'Connor BJ, Barnes PJ. A comparison of low-dose inhaled budesonide plus theophylline and high-dose inhaled budesonide for moderate asthma. New Engl J Med 1997; 337: 1412-1418.
92 Ukena D, Harnest U, Sakalauskas R, et al. Comparison of addition of theophylline to inhaled steroid with doubling of the dose of inhaled steroid in asthma. Eur Respir J 1997; 10: 2754-2760.

93 Lim S, Jatakanon A, Gordon D, Macdonald C, Chung KF, Barnes PJ. Comparison of high dose inhaled steroids, low dose inhaled steroids plus low dose theophylline, and low dose inhaled steroids alone in chronic asthma in general practice. Thorax 2000; 55: 837-841.

94 Culpitt SV, de Matos C, Russell RE, Donnelly LE, Rogers DF, Barnes PJ. Effect of theophylline on induced sputum inflammatory indices and neutrophil chemotaxis in COPD. Am J Respir Crit Care Med 2002; 165: 1371-1376.

95 Barnes PJ. The role of theophylline in severe asthma. Eur Respir Rev 1996; 34: 154S-159S.

96 Heck S, Kullmann M, Grast A, et al. A distinct modulating domain in glucocorticoid receptor monomers in the repression of activity of the transcription factor AP-1. EMBO J 1994; 13: 4087-4095.

97 Jaffuel D, Demoly P, Gougat C, et al. Transcriptional potencies of inhaled glucocorticoids. Am J Respir Crit Care Med 2000; 162: 57-63.

98 Reichardt HM, Kaestner KH, Tuckermann J, et al. DNA binding of the glucocorticoid receptor is not essential for survival. Cell 1998; 93: 531-541.

99 Adcock IM, Nasuhara Y, Stevens DA, Barnes PJ. Ligandinduced differentiation of glucocorticoid receptor transrepression and transactivation: preferential targetting of NF-kB and lack of I-kB involvement. Br J Pharmacol 1999; 127: 1003-1011.

100 Bledsoe RK, Montana VG, Stanley TB, et al. Crystal structure of the glucocorticoid receptor ligand binding domain reveals a novel mode of receptor dimerization and coactivator recognition. Cell 2002; 110: 93-105.

101 Barnes PJ. New treatments for COPD. Nature Rev Drug Disc 2002; 1: 437-445.

102 Ito K, Lim S, Chung KF, Barnes PJ, Adcock IM. Theophylline enhances histone deacetylase activity and restores glucocorticoid function during oxidative stress. Am J Respir Crit Care Med 2002; 165: A625.

103 Cuzzocrea S, Riley DP, Caputi AP, Salvemini D. Antioxidant therapy: a new pharmacological approach in shock, inflammation, and ischemia/reperfusion injury. Pharmacol Rev 2001; 53: 135-159.

104 Hansel TT, Kharitonov SA, Donnelly LE, et al. A selective inhibitor of inducible nitric oxide synthase inhibits exhaled breath nitric oxide in healthy volunteers and asthmatics. FASEB J 2003; 17: 1298-1300.

105 Park JH, Jung Y, Kim TY, et al. Class I histone deacetylase-selective novel synthetic inhibitors potently inhibit human tumor proliferation. Clin Cancer Res 2004; 10: 5271-5281.

106 Greene WC, Chen LF. Regulation of NF- $\kappa B$ action by reversible acetylation. Novartis Found Symp 2004; 259: 208-217.

$107 \mathrm{Fu} \mathrm{M}$, Rao M, Wu K, et al. The androgen receptor acetylation site regulates cAMP and AKT but not ERKinduced activity. J Biol Chem 2004; 279: 29436-29449.

$108 \mathrm{Fu} \mathrm{M}$, Wang C, Zhang X, Pestell RG. Acetylation of nuclear receptors in cellular growth and apoptosis. Biochem Pharmacol 2004; 68: 1199-1208. 